\title{
Effect of Incorporation of an Antimicrobial Monomer 2-tert-Butylaminoethyl Methacrylate on the Flexural Strength and Impact Strength of a Heat-polymerized Acrylic Resin: An In Vitro Study
}

\author{
Bhumika Sharma ${ }^{1}$, Prabal Sharma ${ }^{2}$
}

\begin{abstract}
Aim: To evaluate the effect of incorporation of 2-tert-butylaminoethyl methacrylate (TBAEMA) on the flexural strength and impact strength of a heat-polymerized acrylic resin.

Materials and methods: A total number of 240 specimens were fabricated, 120 each for flexural strength and impact strength. Further, four groups were divided according to the concentration of TBAEMA incorporated to the acrylic resin (DPI): $0 \%, 0.5 \%, 1 \%$ and $2 \%$. Flexural strength and impact strength of the specimens was tested and results were analyzed by ANOVA and Tukey's test ( $p$ value $\leq 0.05$ ).

Results: Significant difference was found for both flexural strength and impact strength ( $p$ value $\leq 0.05$ ).

Conclusion: Within the limitations of this study, it was concluded that the flexural strength and impact strength gets altered, depending on the concentration of TBAEMA.

Keywords: Custom-made metal molds, Denture base, Drawback, Microorganisms, Success.

International Journal of Prosthodontics and Restorative Dentistry (2019): 10.5005/jp-journals-10019-1233
\end{abstract}

\section{InTRODUCTION}

In 1937, Dr Walter Wright introduced poly methyl methacrylate (PMMA) for use as denture base material and found that PMMA fulfilled all the requirements of an ideal denture base material with several advantages such as favorable working characteristics, ease of processing, accurate fit, good color stability, excellent esthetics, and stability in the oral environment. However, it has certain poor mechanical and physical properties. ${ }^{1}$ Another important drawback is that their rough surfaces facilitate the microbial adhesion and colonization, which ultimately induces an inflammatory response in the oral mucosa of denture wearers leading to denture stomatitis, causing a deleterious impact on the person's oral health. ${ }^{2}$

Biofilm formation over complete dentures can be controlled by cleaning methods and overnight removal. However, due to the limited compliance and manual dexterity of some edentulous patients, it would be convenient if denture base materials itself could prevent biofilm formation. ${ }^{3}$ Immersion in certain cleansing and disinfecting solution can affect the mechanical properties as well as surface appearance of denture base resins. ${ }^{4}$ Also, these substances might get released from the resins, leading to toxic effects on the oral mucosa as well. ${ }^{5}$

To overcome these complications, antibacterial denture base material that can kill or strongly resist against microbial growth for preventing biofilms' formation should be taken into consideration. 2-tert Butyl amino ethyl methacrylate (TBAEMA) has been incorporated to PMMA to inhibit microbial growth on the denture surface. Antimicrobial activity is thought to occur because of the pendant amino groups, which arise on acrylic resin surface and display the antimicrobial activity. ${ }^{2}$

Considering the fact that dentures are subjected to repeated flexural forces and are weak in impact strength, it is imperative to

\begin{abstract}
1,2Department of Prosthodontics, MM College of Dental Sciences and Research, Yamunanagar, Haryana, India

Corresponding Author: Bhumika Sharma, Department of Prosthodontics, MM College of Dental Sciences and Research, Yamunanagar, Haryana, India, Phone: +91 9971016414, e-mail: bhumika.sardana@gmail.com
\end{abstract}

How to cite this article: Sharma B, Sharma P. Effect of Incorporation of an Antimicrobial Monomer 2-tert-Butylaminoethyl Methacrylate on the Flexural Strength and Impact Strength of a Heat-polymerized Acrylic Resin: An In Vitro Study. Int J Prosthodont Restor Dent 2019;9(2):47-50.

Source of support: Nil

Conflict of interest: None

evaluate the mechanical properties of acrylic resins after TBAEMA incorporation (in different concentrations). Therefore, the objective of this study was to evaluate the effect of incorporation of different concentrations of TBAEMA on flexural strength and impact strength of heat-polymerized acrylic resins.

\section{Materials and Methods}

This in vitro study was conducted at the Department of Prosthodontics and Crown and Bridge, Subharti Dental College and Hospital, Meerut, Uttar Pradesh (Flowchart 1).

\section{Specimen Fabrication}

Specimens were prepared in the form of denture base acrylic resin rectangular blocks. A custom-made metal mold (length: $65 \mathrm{~mm}$; width: $10 \mathrm{~mm}$; thickness: $3.3 \mathrm{~mm}$ ) was prepared according

(O) The Author(s). 2019 Open Access This article is distributed under the terms of the Creative Commons Attribution 4.0 International License (https://creativecommons. org/licenses/by-nc/4.0/), which permits unrestricted use, distribution, and non-commercial reproduction in any medium, provided you give appropriate credit to the original author(s) and the source, provide a link to the Creative Commons license, and indicate if changes were made. The Creative Commons Public Domain Dedication waiver (http://creativecommons.org/publicdomain/zero/1.0/) applies to the data made available in this article, unless otherwise stated. 
Flowchart 1: Grouping of the specimens

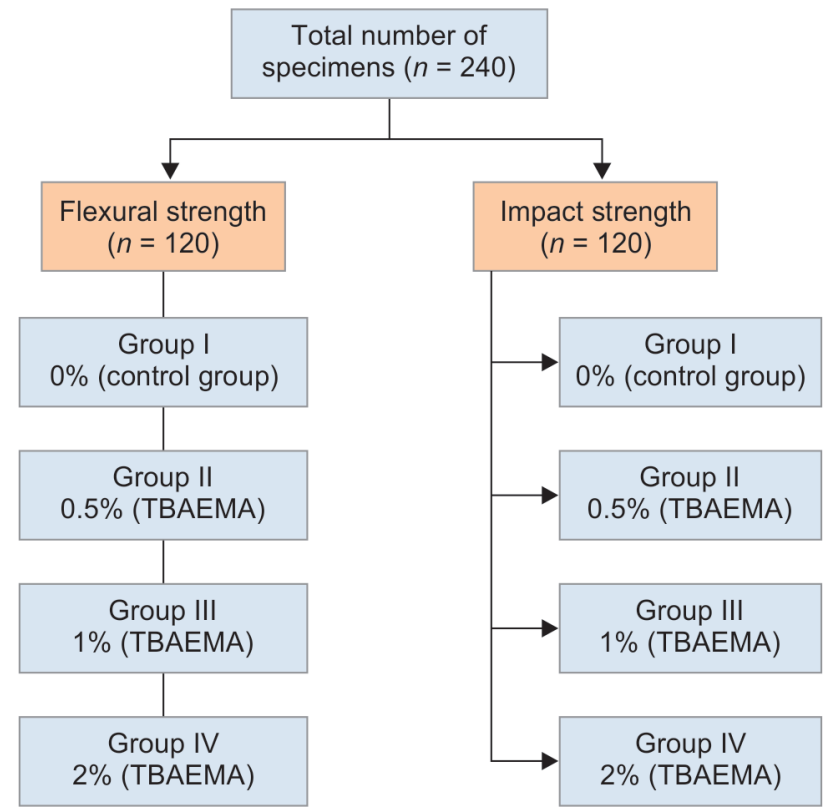

to standardization (ISO/FDIS1567). Petroleum jelly was applied on the inner surface of the mold. Molten modeling wax was poured in the mold. Wax rectangular blocks were removed after the wax hardened. The wax blocks were then invested in metal flasks with dental stone and dewaxing was done. The powder and liquid of denture base acrylic resin was mixed according to the manufacturer's instructions in a porcelain mixing jar with a lid. When the mix reached the dough stage, it was packed in the metal flasks and processed by compression molding technique using a short curing cycle. The procedure was repeated to obtain all the specimens.

\section{Control Group}

All specimens were stored in distilled water at $37^{\circ} \mathrm{C}$ for $50 \pm 2$ hours before testing. These specimens were used as control group and were designated as group I.

\section{Experimental Groups}

The required quantity $(0.05 \mathrm{~mL}, 0.1 \mathrm{~mL}$, and $0.2 \mathrm{~mL}$ for the groups II, III, and IV respectively) of the test sample material (i.e., 2-tertiary butyl amino ethyl methacrylate (TBAEMA)) was measured in a micropipette and dispensed in the porcelain mixing jar. Then the powder and liquid of the denture base acrylic resin was mixed according to the concentration of the sample material. The mix was packed in the metal flasks and processing is done by compression molding technique using a short curing cycle. The procedure was repeated to obtain all the specimens for each experimental group. The acrylic rectangular blocks were then retrieved from flasks and were finished similarly as control specimens. All specimens were stored in distilled water at $37^{\circ} \mathrm{C}$ for $50 \pm 2$ hours before testing. These specimens were used as experimental groups (Fig. 1).

\section{Testing of Specimens}

\section{For Flexural Strength}

The specimens were subjected to 3 point bending test in $\mathrm{HI}-\mathrm{TECH}$ Universal testing machine at a crosshead speed of $5 \mathrm{~mm} /$ minute.

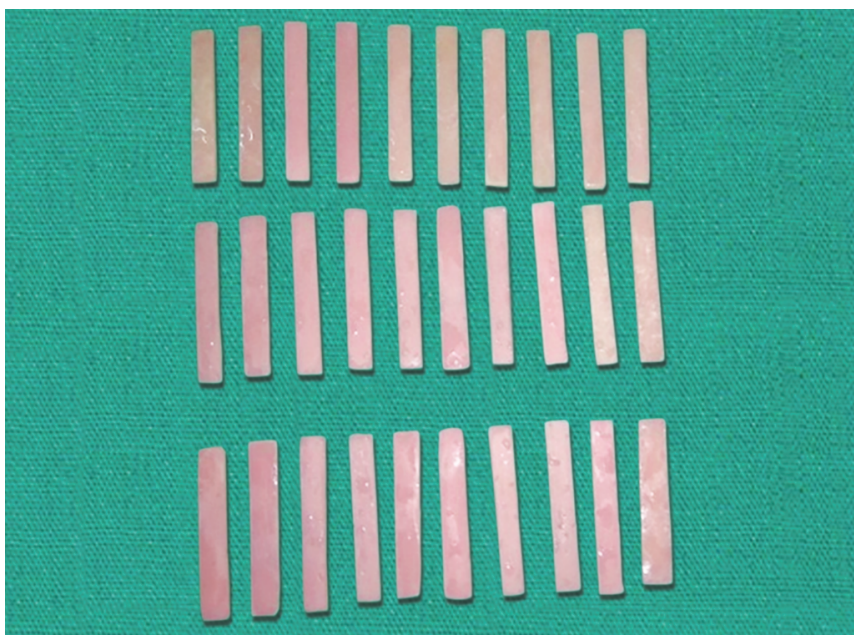

Fig. 1: Specimens fabricated

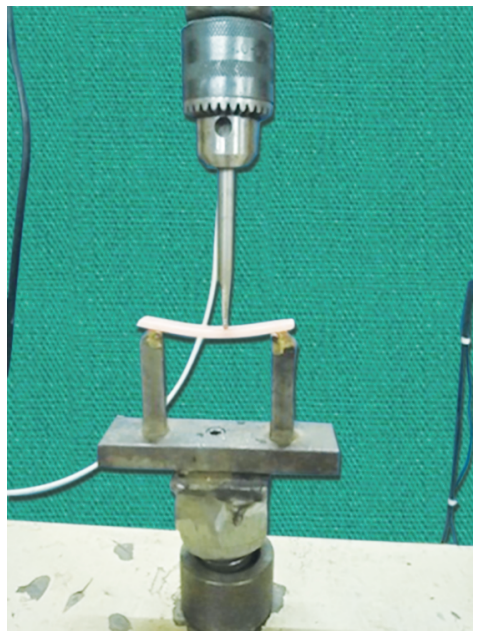

Fig. 2: Flexural strength testing in universal testing machine

The specimens were placed on the jigs $50 \mathrm{~mm}$ apart. A $50 \mathrm{kgf}$ load was applied by a centrally located rod until fracture occurred and the maximum load required to fracture the specimens in each group was recorded (Fig. 2). The load deflection data were collected, tabulated, and studied. The flexural strength was calculated from the following equation: ${ }^{5}$

$$
S=\frac{3 P L}{2 b d^{2}}
$$

where $S=$ flexural strength $(\mathrm{MPa}), P=$ peak load,$L=$ distance between the supports $(50 \mathrm{~mm}), B=$ width of specimen $(10 \mathrm{~mm})$, and $D=$ specimen thickness $(3.3 \mathrm{~mm})$.

\section{For Impact Strength}

The specimens were evaluated by Charpy's impact tester, following ISO standard 179-1:2000. The impact strength was calculated by using a $0.5 \mathrm{~J}$ pendulum by the formula: ${ }^{6}$

$$
\text { Impact strength }=\frac{E \times 10^{3}}{d b}
$$

where $E=$ corrected absorbed energy, $d=$ thickness of the specimen, and $b=$ width of the specimen. The unit in which the impact strength was expressed is $\mathrm{kJ} / \mathrm{m}^{2}$. 


\section{Statistical Analysis}

Statistical analysis was carried out using SPSS (statistical package for social sciences), version 17.5. Mean change in flexural strength and impact strength \pm standard deviation of all acrylic resin specimens in each group was tabulated. An intergroup comparison was done using a one-way ANOVA followed by post hoc Tukey's test HSD and the $p$ value $\leq 0.05$ was considered significant in all tests.

\section{Results}

Mean values and standard deviations for flexural strength are shown in Figure 3.

ANOVA showed statistically significant differences among the groups ( $p$ value $\leq 0.05$ ). Tukey's test showed no statistically significant difference between the group I-i.e. Control (69.14 MPa)-and Experimental group II (70.74 MPa). group III demonstrated intermediate results (63.23 MPa). The lowest flexural strength value was observed for group IV (44.97 MPa).

ANOVA showed statistically significant differences among the groups ( $p$ value $\leq 0.05$ ). Tukey's test showed no statistically significant difference between Control -i.e. group I $\left(10.89 \mathrm{~kJ} / \mathrm{m}^{2}\right)$ and group II $\left(10.91 \mathrm{~kJ} / \mathrm{m}^{2}\right)$. Group III demonstrated intermediate results $\left(9.16 \mathrm{~kJ} / \mathrm{m}^{2}\right)$. The lowest impact strength value was observed for group IV (7.09 kJ/m²) (Fig. 4).

\section{Discussion}

Incorporating substances that could show antimicrobial activity into acrylic resins is a current trend in order to avoid denture stomatitis or related oral diseases. ${ }^{7}$ These includes methacrylic acid (MA), chlorhexidine acetate, methacryloxyundecylpyridinium bromide (MUPB), silver zinc zeolites, acryl amide monomer, silver nanoparticles, and 2-tert-butylaminoethyl methacrylate (TBAEMA). ${ }^{2}$

In this study, 2-tert-butylaminoethyl methacrylate (TBAEMA) was incorporated in different concentrations $(0.5 \%, 1 \%$ and $2 \%)$ into heat-polymerized acrylic resin (DPI) to evaluate the effect on the flexural strength and impact strength on denture base resin. 2-tert-Butylaminoethyl methacrylate (TBAEMA) monomer is a liquid that basically constitutes amino groups. The mechanism of action is due to Pendant amino groups, which might arise on acrylic resin surface and make possible for its antimicrobial activity and inhibition of biofilm formation. ${ }^{8}$

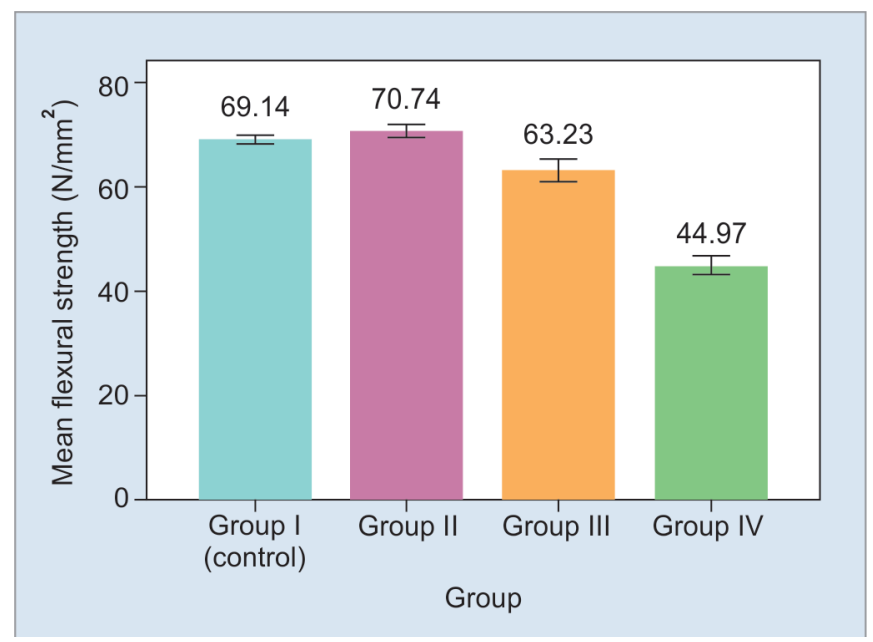

Fig. 3: Mean values and standard deviations for flexural strength
Flexural strength results showed the highest value for group II (70.74 MPa) and lowest for group IV (44.97 MPa), indicating that with the addition of $0.5 \%$ TBAEMA there is an increase in flexural strength; however, it decreases for the $2 \%$ TBAEMA, showing that as concentration of TBAEMA increased, flexural strength decreased. The result was supported by Paleari et al., who concluded that acrylic resin may get softened by the incorporation of TBAEMA and flexural properties decrease with incorporations greater than $1.75 \% .{ }^{8}$ This could be due to an incomplete polymerization process of acrylic resin after the incorporation of TBAEMA and presence of a large amount of residual monomer. Dhir et al. supposed that the changes or decrease in flexural strength could be associated with the dilution of components such as the cross linking agent ethylene glycol dimethacrylate (EGDMA). ${ }^{9}$ Regis et al. stated that the incorporation of increasing amount of an antimicrobial monomer methacrlyoxyundecylpyridinium bromide MUPB (0.6\%) reduces the flexural strength of a proprietary denture base acrylic resin; hardness and surface roughness, however, were not affected by the incorporation of MUPB at 0.3 or $0.6 \%{ }^{3}$ Shibata et al. demonstrated that the degree of conversion of acrylic resin could be negatively affected after the addition of any material, leading to an increase in the content of residual monomer on acrylic resin. ${ }^{10}$

The results of the present study are consistent with previous reports, ${ }^{1,4}(33),(43),(1)$ and (4), which found that the flexural strength value decreased with an increase in the concentration of antimicrobial agents added to the acrylic resin (Table 1).

The mean impact strength was the highest for group II $\left(10.91 \mathrm{~kJ} / \mathrm{m}^{2}\right)$ and the lowest for group IV $\left(7.09 \mathrm{~kJ} / \mathrm{m}^{2}\right)$, showing that the incorporation of only $0.5 \%$ TBAEMA resulted in an increase in impact strength, whereas it drastically decreased for the $2 \%$ TBAEMA, thus indicating that as concentration of TBAEMA increased, impact strength decreased. Asopa et al. stated that the impact strength and surface hardness of the zirconia-reinforced acrylic resin specimens had lesser values when compared to the control specimens. ${ }^{11}$ Castro et al. found in his study that the addition of nanostructured silver vanadate $\left(\beta-\mathrm{AgVO}_{3}\right)$ can provide acrylic resins with antibacterial activity but reduces their impact strength. ${ }^{6}$

Abdallah explained that the incorporation of small percentage (0.3 wt\%) of halloysite nanotubes (HNTs) into PMMA resin produced a significant increase in hardness values, while the flexural strength, impact strength and Young's modulus values did not show a significant increase compared to the control group..$^{12}$ Azeez and

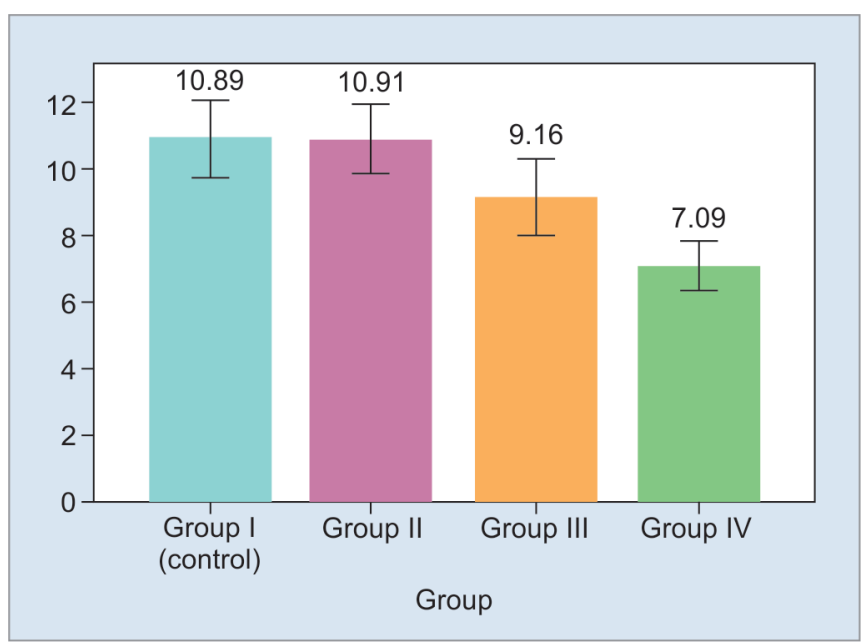

Fig. 4: Mean values and standard deviations for impact strength 
Table 1: Groups evaluated according to the proportion of powder, liquid, and TBAEMA

\begin{tabular}{llll}
\hline $\begin{array}{l}\text { Group }(\%) \\
\text { (TBAEMA) }\end{array}$ & $\begin{array}{l}\text { Powder }(g) \\
(\text { PMMA) }\end{array}$ & $\begin{array}{l}\text { Liquid }(\mathrm{mL}) \\
(\mathrm{MMA})\end{array}$ & TBAEMA $(\mathrm{mL})$ \\
\hline I 0.00 & 21 & 10 & 0 \\
II 0.50 & 21 & 9.950 & 0.05 \\
III 1.00 & 21 & 9.900 & 0.1 \\
IV 2.00 & 21 & 9.800 & 0.2 \\
\hline
\end{tabular}

TBAEMA, 2-tert-butylaminoethyl methacrylate; PMMA, poly(methyl methacrylate); MMA, methyl methacrylate

Fatah evaluated the effect of incorporation of prepared silver zinc zeolite (Ag-Zn Zeolite) on the impact strength of heat-polymerized acrylic denture base materials and concluded that the addition of $0.5 \%$ of $\mathrm{Ag}-\mathrm{Zn}$ zeolite powder to the heat cure acrylic resin had a non-significant effect on the impact strength. ${ }^{5}$

However, this in vitro study has some limitations. Only one commercial available heat-polymerized acrylic resin (DPI) was tested. Incorporation of TBAEMA in another acrylic resin with different polymerization cycle, as microwave-polymerized or autopolymerized acrylic resins could be done to see the effects on their mechanical properties. Also, being an in vitro study, true simulations of oral condition was not possible-i.e., composition and $\mathrm{pH}$ of the saliva and the presence of biofilm.

Thus, within the scope of this study, it was observed that the concentrations of $0.5 \%$ did not seem to alter the studied properties and hence can be recommended for long-term use. However, with addition of $1 \%$ TBAEMA there is no significant change in the flexural strength and impact strength of heat polymerized acrylic resin. TBAEMA in concentration of $2 \%$ greatly reduces the flexural strength and impact strength properties of heat polymerized acrylic resin and hence need to be used with caution when intended to be used for a longer period of time. Hence, it can be documented that as the concentration of antimicrobial agent increases, mechanical properties decreases as also stated by Jagger ${ }^{13}$ and Regis et al. ${ }^{3}$

However, further studies are recommended to investigate the other physical and mechanical properties of acrylic resin after incorporation of TBAEMA. Also, there is a need for microbiological and cytotoxicity tests before these findings can be applied in clinical research.

\section{Conclusion}

Within the limitations of the present in vitro study, it could be concluded that $2 \%$ TBAEMA significantly decreased the flexural strength and impact strength of a heat-polymerized acrylic resin. However, with the addition of $0.5 \%$ TBAEMA, no significant increase or decrease in flexural strength and impact strength was observed. It may be suggested from the present study that TBAEMA in the concentration of $0.50 \%$ can be used as an antimicrobial agent for incorporation into a heat-polymerized acrylic resin without altering the properties of a denture base resin.

\section{References}

1. Peyton FA. History of resins in dentistry. Dent Clin North Am 1975;19(2):211-222.

2. Rodriguez LS, Paleari AG, et al. Chemical Characterization and Flexural Strength of a Denture Base Acrylic Resin with Monomer 2-TertButylaminoethyl Methacrylate. J Prosthodont 2013;22(4):292-297. DOI: 10.1111/j.1532-849X.2012.00942.x.

3. Regis RR, Zanini AP, et al. Physical Properties of an Acrylic Resin after Incorporation of an Antimicrobial Monomer. J Prosthodont 2011; 20(5):372-379. DOI: 10.1111/j.1532-849X.2011.00719.x.

4. Raj N, D'Souza M. Comparison of Transverse Strength of Denture Base Resin on Immersion for Varying Time Period in Water and Denture Cleansers - An In Vitro Study. Asian J Oral Health \& Allied Sci 2011;1(2):56-67.

5. Azeez ZA, Fatah NA. The effect of incorporation of prepared Ag-Zn Zeolite on some properties of heat polymerized acrylic denture base materials. J Bagh College Dentistry 2015;27(1):63-69. DOI: 10.12816/0015266.

6. de Castro DT, Valente MLC, et al. In vitro study of the antibacterial properties and impact strength of dental acrylic resins modified with a nanomaterial. J Prosthet Dent 2015;6:1-8.

7. Pesci-Bardon C, Fosse $\mathrm{T}$, et al. In vitro antiseptic properties of an ammonium compound combined with denture base acrylic resin. Gerodontology 2006;23(2):111-116. DOI: 10.1111/j.17412358.2006.00088.x.

8. Paleari AG, Marra J, et al. Effect of incorporation of 2-tertbutylaminoethyl methacrylate on flexural strength of a denture base acrylic resin. J Appl Oral Sci 2011;19(3):195-199. DOI: 10.1590/ S1678-77572011000300003.

9. Dhir G, Berzins DW, et al. Physical properties of denture base resins potentially resistant to Candida adhesion. J Prosthodont 2007;16(6): 465-472. DOI: 10.1111/j.1532-849X.2007.00219.x.

10. Shibata $T$, Hamada $N$, et al. Antifungal effect of acrylic resin containing Apatite-coated $\mathrm{TiO}_{2}$ photocatalyst. Dent Mater J 2007;26(3):437-444. DOI: $10.4012 / \mathrm{dmj} .26 .437$.

11. Asopa V, Suresh S, et al. A comparative evaluation of properties of zirconia reinforced high impact acrylic resin with that of high impact acrylic resin. Saudi J Dent Res 2015;6(2):146-151. DOI: 10.1016/ j.sjdr.2015.02.003.

12. Abdallah RM. Evaluation of polymethyl methacrylate resin mechanical properties with incorporated halloysite nanotubes. J Adv Prosthodont 2016;8(3):167-171. DOI: 10.4047/jap.2016.8.3.167.

13. Jagger RG. Effect of the curing cycle on some properties of a polymethylmethacrylate denture base material. J Oral Rehabil 1978;5(2):151-157. DOI: 10.1111/j.1365-2842.1978.tb01208.x. 